\title{
Ellagic acid alleviates adjuvant induced arthritis by modulation of pro- and anti- inflammatory cytokines
}

\author{
GAMAL ALLAM ${ }^{1,2}$, EMAD A. MAHDI ${ }^{3,4}$, ABDULLAH M. ALZAHRANI, \\ ABDELAZIZ S. ABUELSAAD ${ }^{I, 2}$ \\ ${ }^{1}$ Immunology Section, Department of Microbiology, College of Medicine, Taif University, Taif, Saudi Arabia \\ ${ }^{2}$ Immunology Section, Department of Zoology, Faculty of Science, Beni-Suef University, Beni-Suef, Egypt \\ ${ }^{3}$ Department of Biology, Faculty of Science, Taif University, Taif, Saudi Arabia \\ ${ }^{4}$ Department of Pathology, Faculty of Veterinary Medicine, Beni-Suef University, Beni-Suef, Egypt \\ ${ }^{5}$ Orthopedic Section, Department of Surgery, College of Medicine, Taif University, Taif, Saudi Arabia
}

\begin{abstract}
Rheumatoid arthritis (RA) is a chronic inflammatory disease of unknown aetiology, but it is now clear that pro-inflammatory cytokines play a central role in its pathogenesis. Ellagic acid (EA) has a variety of biological activities including anti-oxidant, anti-inflammatory, and anti-cancer properties. The aim of the present study was to evaluate the potential effect of ellagic acid on the prevention and/ or treatment of adjuvant induced arthritis (AIA) model in mice. Ellagic acid treatment was started one week before AIA induction and continued for three weeks after induction of AIA. Ellagic acid treatment significantly $(p<0.01)$ inhibited foot paw oedematous swelling and attenuated AIA-associated pathology. Ellagic acid significantly $(p<0.01)$ reduced serum levels of pro-inflammatory cytokines: interleukin $1 \beta$ (IL-1 $\beta)$, tumor necrosis factor $\alpha(T N F-\alpha)$, and interleukin 17 (IL-17). However, serum levels of IL-10 and interferon $\gamma($ IFN- $\gamma$ ) significantly increased ( $p<0.01$ and $p<0.05$, respectively), while serum level of transforming growth factor $\beta$ (TGF- $\beta$ ) did not significantly alter with EA treatment. In conclusion, these results suggest that EA attenuated AIA-associated pathology in the mouse model by downregulation of pro-inflammatory cytokines and upregulation of anti-inflammatory cytokines.
\end{abstract}

Key words: adjuvant induced arthritis, ellagic acid, pro-inflammatory cytokine, anti-inflammatory cytokine.

(Cent Eur J Immunol 2016; 41 (4): 339-349)

\section{Introduction}

Rheumatoid arthritis (RA) is a systemic autoimmune disease characterised by inflammation of the synovia, synovial hyperplasia with increased cell density, and infiltration of inflammatory cells leading to pannus formation and irreversible cartilage and bone destruction [1]. It affects about $0.5-1 \%$ of the world population, with more women being affected than men, and its incidence increases with increasing age [2-4]. The exact cause of RA is unknown, but genetic and environmental factors are contributory [4]. However, it is now clear that inflammatory cytokines such as tumour necrosis factor $\alpha$ (TNF- $\alpha$ ), interleukin $1 \beta$ (IL-1 $\beta$ ), and IL- 6 are overexpressed in RA joints and play an important role in its pathogenesis $[5,6]$. In addition, the current view of the cytokine network in RA joints supports the notion that TNF- $\alpha$ activates a cytokine cascade characterised by simultaneous production of proinflammatory cytokines such as IL-1 $\beta$ and IL-6, whereas anti-inflammatory cytokines such as IL-10 and soluble TNF receptor are suppressed [2, 7]. Long-term use of biological agents targeting TNF- $\alpha$ gives rise to sustained improvement in symptoms and signs of RA. In addition, TNF- $\alpha$ blockade protects joints from structural damage [8]. Although TNF- $\alpha$ has been hypothesised to be the "master cytokine" driving joint inflammation, about $50 \%$ of patients with RA do not respond to anti-TNF therapy [9].

The pathogenesis of RA can involve either the inappropriate activation of $\mathrm{T}$ cells or the lack of appropriate suppression of $\mathrm{T}$ cells [10]. It was found that $\mathrm{CD} 4^{+}$ $\mathrm{T}$ cells from patients with RA express some striking abnormalities in their differentiation into effector cells, in their functional capabilities, and in their responsiveness to regulatory forces. A shift in the Th1/Th2 balance toward Th1 has been described in patients with RA, and

Correspondence: Prof. Gamal Allam, Immunology Section, Department of Microbiology, College of Medicine, Taif University, 888 Taif, Saudi Arabia, e-mail: gm_allam@yahoo.com Submitted: 21.10.2015; Accepted: 8.12.2015 
this also has prognostic value for the course of the disease $[11,12]$. The intrinsic bias to Th17 cell differentiation as observed defines a novel aspect of abnormal CD4 ${ }^{+}$ $\mathrm{T}$ cell biology in RA and provides additional evidence of an important role of altered $\mathrm{CD} 4^{+} \mathrm{T}$ cell biology in the pathogenesis of rheumatoid inflammation [13]. Th17 is the pivotal driving force of autoimmune inflammation in several animal models of human autoimmune diseases, including collagen-induced arthritis (CIA) [14] and adjuvant-induced arthritis (AIA) [15]. The inhibition of Th17 cells occurs via the neutralisation of IL-6, a critical Th17 cell-inducing cytokine in mice, leading to suppression CIA [16] and prevention of the onset of AIA [15]. Interleukin 17 exerts potent proinflammatory and joint-destructive activities. The mechanisms orchestrating the cellular pathogenesis and the impact of Th17 cells on the pathogenesis of autoimmune arthritides is therefore unknown but would be important to understand, not least because of the novel treatment strategies being utilised to inhibit Th17 cell effector functions via the neutralisation of IL-17 [13].

Ellagic acid (EA) is a phenolic compound found in a wide variety of nuts and fruits [17-19]. Interest in EA has increased recently due to its potential anti-inflammatory properties. Ellagic acid mediates its anti-inflammatory effects via the modulation of NF- $\mathrm{KB}$ activity and by inhibiting IL-1 $\beta$-induced nuclear translocation of p65 and p50 [20]. Several studies have shown that EA modulates both pro-inflammatory and anti-inflammatory cytokine production. EA decreases production of IL-13 and TNF- $\alpha$ from stimulated human peripheral blood mononuclear cells (PBMC), whereas no change was observed in IL-4 production [21]. Ellagic acid significantly down-regulates mRNA expression and lowers cardiac levels of IL-1 $\beta$, IL-6, TNF- $\alpha$, and monocyte chemoattractant protein (MCP)-1 [22]. Moreover, EA lowers renal levels of IL-6, IL-1 $\beta$, TNF- $\alpha$, and MCP-1, and down-regulates TNF- $\alpha$ and MCP-1 mRNA expression in the kidney. In addition, intake of EA substantially decreases renal IL-1 $\beta$, IL-6, and TNF- $\alpha$ levels in diabetic mice [23]. Topical application of EA diminishes production of pro-inflammatory cytokines IL-1 $\beta$ and IL-6, and blocks infiltration of inflammatory macrophages in the integuments of SKH-1 hairless mice exposed to UV-B [24]. Treatment of gastric ulcerated mice with EA significantly reduces pro-inflammatory cytokine (TNF- $\alpha$, IL-1 $\beta$, and IL-6) levels and induces anti-inflammatory cytokines (IL-4 and IL-10) [25]. EA shows strong inhibition of neutrophilic infiltration as well as suppression of TNF- $\alpha$ and IL-1 $\beta$ in AIA [26]. Furthermore, EA treatment leads to reduced bronchoalveolar lavage fluid levels of IL-6 and increased levels of IL-10 [27].

Taken together, EA has been shown to down-modulate pro-inflammatory mediators and stimulate the production of anti-inflammatory cytokines. Therefore, EA may have a potential role in the prevention and/or treatment of RA.
The aim of the present study was to investigate the potential effect of EA in prevention and/or treatment of AIA.

\section{Material and methods}

\section{Animals}

Eight-week-old MF1 male mice were purchased from the King Fahd Centre for Medical Research, College of Medicine, King Abdulaziz University, Jeddah, Saudi Arabia. The mice were maintained at $22 \pm 2^{\circ} \mathrm{C}$ with a 12 -hour (h) light/dark cycle, housed in a specific pathogen-free environment, and fed standard rodent chow and given water ad libitum. All procedures were performed with the approval of the Institutional Animal Care and Research Ethics Committee.

\section{Drugs and chemicals}

All reagents were purchased from Sigma Chemical Co. (St. Louis, MO, USA) unless otherwise stated. All the chemicals used were of analytical grade.

\section{Induction of arthritis and treatment schedule}

MF1 mice were induced with Complete Freund's Adjuvant (CFA) containing Mycobacterium (M.) tuberculosis, a subcutaneous injection of $0.02 \mathrm{ml} \mathrm{CFA} \mathrm{containing}$ $5 \mathrm{mg} / \mathrm{ml}$ of heat-killed $M$. tuberculosis into a foot pad of the right hind limb [28]. This arthritis model, called adjuvant-induced arthritis (AIA), has been widely used as a model for rheumatoid arthritis [29]. Ellagic acid was dissolved in pure dimethyl sulfoxide (DMSO), and then diluted with phosphate buffer saline (PBS, pH 7.2) to a final DMSO concentration equal to $2 \%(\mathrm{v} / \mathrm{v})$. EA suspension was administered intraperitoneally (i.p.) at a total dose of $700 \mathrm{mg} / \mathrm{kg}$ body weight divided equally into 12 injections with three injections/week for four consecutive weeks, commencing one week before subplantar injection with CFA containing $M$. tuberculosis. The arthritic control (AC) and normal control (NC) mice groups were given the same amount of the vehicle (2\% DMSO) at the same time as the arthritic treated (AT) and normally treated (NT) mice. The dose of EA and route of administration were selected according to Soh et al. [30], who reported that mice treated with up to $1000 \mathrm{mg} / \mathrm{kg} /$ day by intraperitoneal route for four consecutive days did not show any mortality until day 30 post treatment.

\section{Blood sampling}

At the end of the third week post arthritis induction (the fourth week post treatment) mice were anesthetised by ether inhalation and blood was collected. Sera were collected from the clotted blood samples after centrifugation at $400 \mathrm{~g}$ for 15 minutes ( $\mathrm{min}$ ), then divided into aliquots and stored at $-80^{\circ} \mathrm{C}$ until use. 


\section{Measurement of arthritis severity}

The thickness of the right hind paws was measured with Vernier callipers every third day commencing on the first day of arthritis induction (0 day), and the values obtained were used as an index of foot paw oedematous swelling. The percentage reduction of paw swelling in the test drug-treated group was calculated by using the following formula according to Shruthi et al. [31]. 100 ,

$\%$ Reduction in paw swelling $(\mathrm{RPS})=1-(\mathrm{Vt} / \mathrm{Vc}) \times$

where $\mathrm{Vt}=$ paw swelling in the test drug-treated animals; $\mathrm{Vc}=$ paw swelling in the control group animals.

\section{Histopathological investigations}

After sacrifice (21 days after arthritis induction), the right ankles and hind paws were removed and placed in $10 \%$ buffered formalin for 48 hours. The skin of paws dorsi were incised longitudinally, and their nails were removed to accelerate the decalcification process. Decalcification was performed with $10 \%$ EDTA $\left(\mathrm{pH} \mathrm{7.4)}\right.$ ) at $18^{\circ} \mathrm{C}$. EDTA solution was replaced twice weekly for seven weeks, and the end point of decalcification was assessed physically with a surgical blade. After complete decalcification, the samples were washed with PBS, dehydrated in a graded ethanol series, and embedded in paraffin wax. Sagittal sections measuring $5 \mu \mathrm{m}$ in thickness were prepared and stained with haematoxylin and eosin (H\&E) [32-34].

Histological examinations of synovial inflammation, cartilage, and bone damages were performed by a pathologist blindly. Sections were graded according to the system described by Sancho et al. [35] for synovial hypertrophy (pannus formation), inflammation (mononuclear cell infiltration), cartilage destruction, and bone erosion. A 0-3-point scale used for each parameter $(0=$ normal, $1=$ mild inflammation, $2=$ moderate inflammation, $3=$ severe inflammation). The maximum possible score was 12 .

\section{Cytokine measurements}

Serum levels of IL-1 $\beta$, IL-10, IL-17, TNF- $\alpha$, IFN- $\gamma$, and transforming growth factor $\beta$ (TGF- $\beta$ ) were estimated by using high-sensitivity sandwich ELISA kit (abcam $^{\circledR}$, Cambridge, UK) according to the manufacturer's instructions. Briefly, a monoclonal antibody specific for each cytokine (IL- $1 \beta$, IL-10, IL-17, TNF- $\alpha$, IFN- $\gamma$, and TGF- $\beta$ ) was coated onto wells of the microtiter plates provided. Samples and standards of known concentrations were applied into plates. After the incubation period, the biotinylated monoclonal antibodies specific for IL- $1 \beta$, IL-10, IL-17, TNF- $\alpha$, IFN- $\gamma$, and TGF- $\beta$ were added and incubated for one hour with gentle shaking. After washing, the enzyme Streptavidin-HRP that binds biotinylated antibody was added and incubated for 45 minutes at room temperature with gentle shaking. TMB substrate solution was added and the plates were incubated in the dark for 30 minutes at room temperature. The reaction was stopped by using $2 \mathrm{~N} \mathrm{HCl}$ and the absorbance was measured at 450 nm using a microplate reader (BioTech, CA, USA). Cytokine concentrations were determined by reference to standard curve construction.

\section{Data analysis}

Statistical tests were performed with SPSS (version 16) software. Significant differences were determined by two-tailed $t$-test for comparisons between two groups and one-way analysis of variance (ANOVA) with application of Tukey's test for multiple comparisons. Results were expressed as mean \pm standard deviation (SD) and values of $p>0.05$ were considered statistically insignificant, while those of $p<0.05$ and $p<0.01$ were considered statistically significant and highly significant, respectively.

\section{Results}

\section{Ellagic acid attenuates pathological manifestations in an adjuvant-induced arthritis mice model}

To evaluate the potential anti-arthritic activity of EA, arthritis was induced by sub-plantar administration with CFA containing $M$. tuberculosis into the foot pad of the right hind limb. EA-treated mice received 12 doses of $\mathrm{EA}$, three injections per week, each of $58.33 \mathrm{mg} / \mathrm{kg}$ body weight. Treatment with EA started one week before immunisation with CFA and continued for three weeks after arthritis induction. Arthritis severity was assessed by measuring foot paw swelling every three days. Immediately before injection of CFA, on day 0 , there was no significant difference $(p>0.05)$ in foot paw thickness of the right hind limb of normal control (NC, $n=15$ ), normal treated (NT, $n=15$ ), arthritic control (AC, $n=15$ ), and arthritic treated (AT, $n=15$ ) mice groups (Table 1). Individuals of both $\mathrm{NC}$ and NT groups showed no gross pathological lesions in the right hind paws, digits, and ankles. At each time interval throughout the experiment, foot paw thickness of NT and NC mice did not significantly change $(p>0.05$, Table 1). On the other hand, clinically apparent arthritis developed at day 3 in all AIA mice and reached the peak at day 6 (Table 1), with marked swelling and redness of hind paws. AC mice showed rapid and marked progress. The right hind paws of AC mice revealed marked congestion and swelling (extending to involve digits and ankles of some individuals). However, the right hind paws of AT mice revealed a similar gross pathological picture but of moderate degree. Throughout the time of the experiment, EA treatment significantly $(p<0.01)$ reduced foot paw swelling of AT as compared to AC mice, and the highest reduction percentage was $17.79 \%$ at day 21 (Table 1 ). 
Table 1. Effect of ellagic acid administration on foot paw oedematous swelling (mm)

\begin{tabular}{ccccccc}
\hline Time/day & NC & NT & AC & AT & \% RPS & $p$ value \\
\hline 0 & $2.31 \pm 0.20^{\mathrm{a}}$ & $2.31 \pm 0.20^{\mathrm{a}}$ & $2.31 \pm 0.20^{\mathrm{a}}$ & $2.31 \pm 0.20^{\mathrm{a}}$ & 0 & $>0.05$ \\
\hline 3 & $2.31 \pm 0.20^{\mathrm{a}}$ & $2.32 \pm 0.12^{\mathrm{a}}$ & $3.81 \pm 0.16^{\mathrm{b}}$ & $3.38 \pm 0.21^{\mathrm{c}}$ & 11.29 & $<0.01$ \\
\hline 6 & $2.53 \pm 0.37^{\mathrm{a}}$ & $2.40 \pm 0.17^{\mathrm{a}}$ & $3.91 \pm 0.25^{\mathrm{b}}$ & $3.43 \pm 0.21^{\mathrm{c}}$ & 12.28 & $<0.01$ \\
\hline 9 & $2.53 \pm 0.37^{\mathrm{a}}$ & $2.40 \pm 0.17^{\mathrm{a}}$ & $3.91 \pm 0.15^{\mathrm{b}}$ & $3.40 \pm 0.22^{\mathrm{c}}$ & 13.04 & $<0.01$ \\
\hline 12 & $2.60 \pm 0.13^{\mathrm{a}}$ & $2.59 \pm 0.21^{\mathrm{a}}$ & $3.85 \pm 0.46^{\mathrm{b}}$ & $3.30 \pm 0.18^{\mathrm{c}}$ & 14.29 & $<0.01$ \\
\hline 15 & $2.68 \pm 0.13^{\mathrm{a}}$ & $2.70 \pm 0.28^{\mathrm{a}}$ & $3.85 \pm 0.53^{\mathrm{b}}$ & $3.27 \pm 0.18^{\mathrm{c}}$ & 15.07 & $<0.01$ \\
\hline 18 & $2.76 \pm 0.17^{\mathrm{a}}$ & $2.72 \pm 0.11^{\mathrm{a}}$ & $3.87 \pm 0.33^{\mathrm{b}}$ & $3.19 \pm 0.14^{\mathrm{c}}$ & 17.57 & $<0.01$ \\
\hline 21 & $2.85 \pm 0.16^{\mathrm{a}}$ & $2.85 \pm 0.39^{\mathrm{a}}$ & $3.71 \pm 0.44^{\mathrm{b}}$ & $3.05 \pm 0.21^{\mathrm{c}}$ & 17.79 & $<0.01$ \\
\hline
\end{tabular}

Mice were monitored on daily basis, and thickness of the right hind paws were measured every three days during the experiment. Percentage reduction in paw swelling $(R P S)$ was calculated using the following formula: $\% R P S=1-(V t / V c) \times 100$, where $V t=$ paw swelling in the test drug treated animals, Vc $=$ paw swelling in the arthritic control group animals. Data are presented as mean $\pm S D$ of 15 mice per group. For each time interval, values not sharing common superscripts denote significant differences.

$N C$ - normal control mice, NT - normal treated mice, AC - arthritic control mice, AT-arthritic treated mice.

\section{Ellagic acid ameliorates histopathological alterations in AIA mice}

In order to investigate the effect of EA treatment on arthritic histopathology, the right ankles and hind paws were removed after sacrifice on the $21^{\text {st }}$ day post arthritis induction and processed for histopathological examinations. As shown in Fig. 1, H\&E stained sections of paws and digits tissues from both normal control (NC) and normal treated (NT) mice revealed no inflammation. However, stained sections of arthritic control (AC) mice revealed marked histopathological changes in the form of synovial hyperplasia, with a large number of inflammatory cells (lymphocytes, macrophages, and sometimes plasma cells), extensive pannus formation, and severe cartilage destruction. On the other hand, arthritic-treated (AT) mice showed less severe arthritis pathology with moderate inflammation (Fig. 1).

Concerning AC mice, microscopic examination showed synovitis characterised by proliferating synovial lining cells, in 2-3 layers, as well as proliferation of the underlying blood vessels, which was associated with perivascular oedema and diffuse cellular infiltrates composed of mononuclear cells (Fig. 2A). In many specimens, the inflammatory cellular exudates extended to involve whole periarticular soft tissues of the connective tissue and muscles. There was synovial sloughing in some areas of synovial membrane and mild proliferative lesion of fibroblast-like cells. Pannus formation was in the form of single or multiple proliferating granulation tissues containing hyperplastic synoviocytes and inflammatory cells at the articular cartilage margin, and at the cartilage-bone level. The articular cartilages of some arthritic mice had uneven articular surface and demonstrated superficial fibrillation accompanied by cell death or proliferation and in some cases extended to the mid-zone portion of the articular cartilage. Moreover, the articular bone destruction was visualised by osteoclast activity and fibroplasia (Fig. 2). However, AT mice showed the previously mentioned histopathological lesions of arthritis, but with mild to moderate degree (Fig. 2, AT).

\section{Ellagic acid reduces histopathological arthritis score in AIA mice}

Histologic analysis of synovitis, pannus formation, bone erosion, and cartilage destruction were scored on a 0-3 scale in H\&E-stained sections by a blinded observer. The present data revealed a high significant $(p<0.01)$ reduction in the total histopathological score of AT mice compared to AC ones (Fig. 3). In detail, EA treatment significantly $(p<0.01)$ attenuated the synovitis, reduced pannus formation, and decreased bone resorption in treated mice, compared to control mice. However, cartilage destruction in AT mice did not change significantly $(p>$ 0.05) as compared to AC mice (Fig. 3).

\section{Ellagic acid downregulates pro-inflammatory cytokines and upregulates anti-inflammatory cytokines in AIA mice}

To investigate the anti-inflammatory effect of EA on the AIA model, IL-1 $\beta$, IL-10, IL-17, TNF- $\alpha$, IFN- $\gamma$, and TGF- $\beta$ were quantified in the serum on the $21^{\text {st }}$ day post-arthritic induction, using standard sandwich ELISA procedures. As depicted in Table 2, circulating levels of IL-1 $\beta$ and TNF- $\alpha$ did not change significantly $(p>0.05)$ in normal mice with EA treatment, compared to NC mice. However, AC mice showed high significant $(p<0.01)$ serum levels of both IL- $1 \beta$ and TNF- $\alpha$, compared to NC mice. Nevertheless, AT mice showed a high significant $(p<0.01)$ reduction in the circulating levels of both IL-1 $\beta$ and TNF- $\alpha$, compared to AC mice.

Ellagic acid treatment did not significantly $(p>0.05)$ affect circulating levels of IL-17 in normal (NT) mice, compared to NC mice. At the same time, IL-17 levels of 

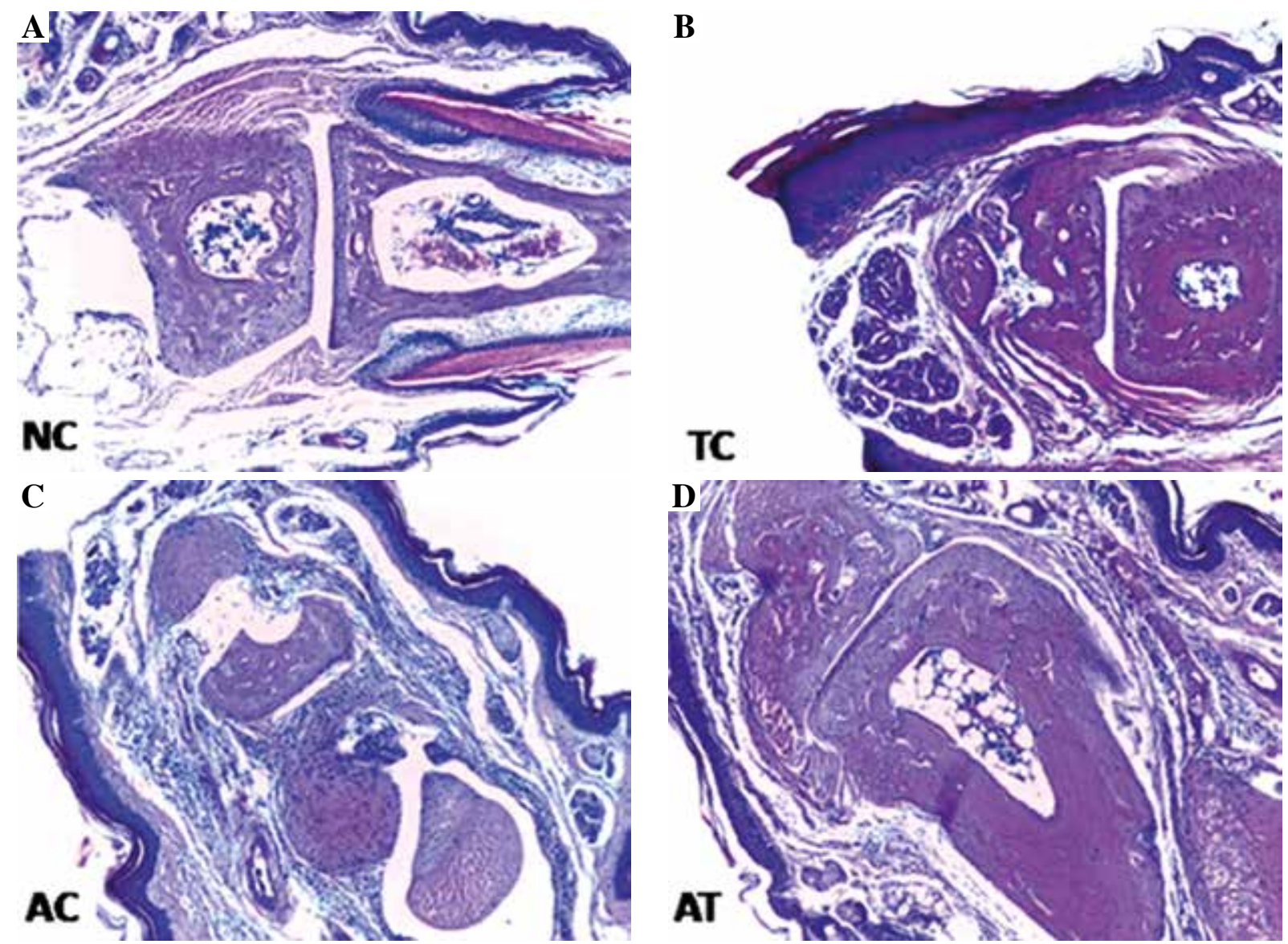

Fig. 1. Histopathological evaluation of ellagic acid treatment on adjuvant induced arthritis in mice. Representative results showing the histopathological picture of hind paws and digits of normal control (NC), normal treated (NT), arthritic control (AC) and arthritic treated (AT) mice in H\&E (100x) stained sections. The normal histological picture of hind paws joints was presents in both NC and NT mice. AC mice showed synovial hyperplasia, inflammatory cells infiltration, pannus formation, and cartilage destruction; whereas AT mice revealed less severity of arthritis pathology

AC mice were significantly $(p<0.01)$ increased compared to $\mathrm{NC}$ ones. However, the serum levels of IL-17 significantly $(p<0.01)$ decreased in AT mice, compared to the AC group. Interestingly, there was no significant difference $(p>0.05)$ in IL-17 levels of NC, NT, and AT mice (Table 2).

The serum levels of IFN- $\gamma$ did not significantly $(p>0.05)$ change in AC mice, compared to the NC group. However, circulating levels of IFN- $\gamma$ significantly $(p<0.05)$ increased in NT and AT mice compared to NC and $\mathrm{AC}$ groups, respectively. Meanwhile, there was no significant difference $(p>0.05)$ in circulating concentrations of IFN- $\gamma$ between NT and AT mice (Table 2).

Transforming growth factor $\beta$ serum levels of normal (NT) mice did not significantly $(p>0.05)$ change with EA treatment, compared to NC animals. Circulating concentrations of TGF- $\beta$ decreased in AC mice, but not significantly $(p>0.05)$ differently than those of NC mice. On the other hand, EA treatment significantly $(p<0.01)$ decreased
TGF- $\beta$ levels of arthritic (AT) mice, compared to NC mice. Transforming growth factor $\beta$ levels of AT mice decreased more that of AC animals; however, such a decrease was not significantly $(p>0.05)$ different (Table 2$)$.

Interleukin 10 serum levels of NT mice did not differ significantly $(p>0.05)$ from that of NC animals, but significantly $(p<0.01)$ increased compared to those of AC and AT mice groups. AC mice showed significantly $(p<0.01)$ decreased circulating levels of IL-10, compared to NC mice. However, IL-10 levels of AT mice significantly $(p<0.01)$ increased, compared to AC mice. Meanwhile, there was no significant difference $(p>0.05)$ in IL-10 levels between AT and NC mice (Table 2).

\section{Discussion}

Even though several studies have been performed, an efficient medicine for RA treatment still has not been found [31]. Due to the lack of efficacy and major side ef- 

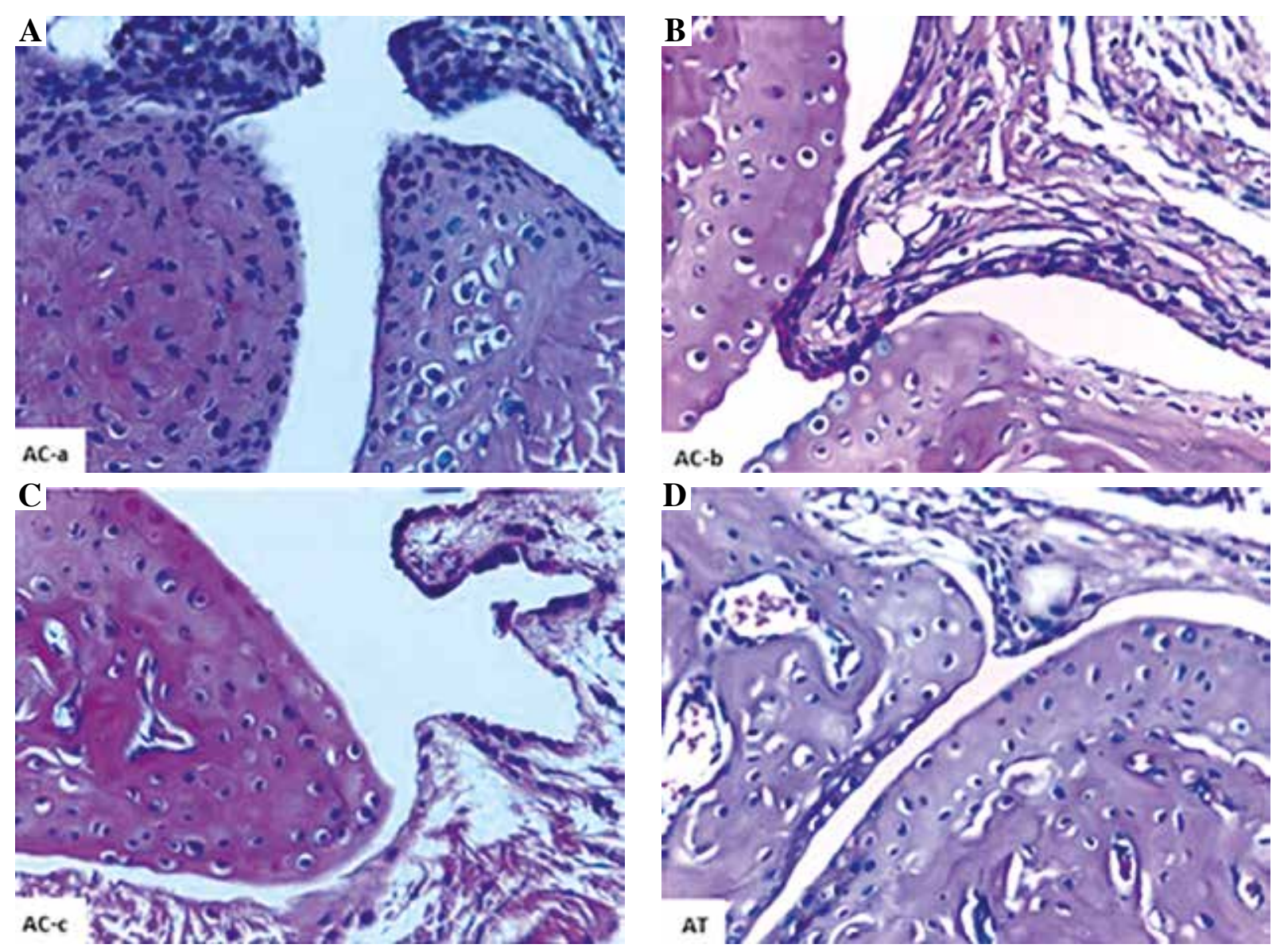

Fig. 2. Representative photomicrographs showing the histopathological picture of hind paws and digits of arthritic control (AC) and arthritic treated (AT) mice in H\&E stained sections ( $\times 400)$. AC mice showed hyperplastic synovial membrane composed of multiple layers of synoviocytes (AC-a), marked pannus formation and fibroplasia of the underlying connective tissues associated with cartilage erosion and bone resoprption (AC-b), and multiple panni were formed from synovial membrane (AC-c). However, AT mice revealed mild pannus formation, fibroplasias, cartilage erosion and bone resoprption (AT)

fects related to many medical treatments, a wide variety of botanicals are used to treat RA [36, 37]. The current study was conducted to evaluate the preventive and treatment potential of EA on the AIA model in mice. This arthritis model is a convenient rodent model of RA [38]. In this study, EA was administered intraperitoneally because absorption seems to be higher by this route than by oral administration [30]. Previous studies on oral administration of EA have found that $10 \%$ of the dose given to rats was absorbed and excreted as a metabolite in urine and faeces [39], whereas mice given higher doses showed absorption rates of $28 \%$ [40].

Bioavailability and metabolism of EA in mice following i.p. administration are not fully understood and need further investigation. However, studies with oral intake of EA or its natural sources have contributed to shedding light on EA metabolism. Urolithins are considered as biomarkers of human exposure to dietary EA derivatives [41].
Several studies have shown that urolithins appear in human systemic circulation within a few hours after pomegranate product consumption, reaching maximum concentrations at between 24 and 48 hours. They are present in plasma and urine for up to 72 hours, in free and conjugated forms [42-44]. In the current study, mice were injected with EA every 48 hours. Therefore, we assumed that the concentration of EA in plasma was not decreased and could reach biological targets at relevant concentration.

Data from the present study showed that sub-planter injection of CFA significantly increased foot paw oedematous swelling and arthritis score. The pathogenesis for development of AIA following injection of atherogenic preparations is not fully understood. However, the influx and/or local activation of mononuclear cells (including T cells, B cells, plasma cells, dendritic cells, macrophages, and mast cells), and by angiogenesis, is the cause of synovitis. Leukocytes and other cells in the synovial tissue 
produce several inflammatory mediators, including chemokines and chemotactic cytokines that recruit more leukocytes and inflammatory cells to the inflamed joint and enhance angiogenesis $[45,46]$. The synovial membrane becomes hyperplastic and extends to form villi. The osteoclast-rich portion of the synovial membrane, or pannus, destroys bone whereas enzymes secreted by neutrophils, synoviocytes, and chondrocytes degrade cartilage [4749]. Histopathological investigations of this study showed slight cartilage destruction, bone resorption, periosteal proliferation, and marked synovitis, as well as periarticular inflammation in arthritic untreated mice. Treatment with EA largely retrieved such pathological manifestations. Our data also showed that EA treatment significantly reduced foot paw oedematous swelling, arthritis score, and disease-associated hyperalgesia. These results are in accord with previous studies that have demonstrated that treatment with EA reduced paw oedema in the AIA rat model [31]. Bulani et al. [50] reported that ellagic acid hydroxypropyl- $\beta$-cyclodextrin treatment attenuates disease progression and associated hyperalgesia in CFA-induced arthritic rats. Moreover, red raspberry fruit extract containing EA reduced the severity of arthritis by inhibition of inflammation, pannus formation, cartilage damage, and bone resorption in both CIA [51] and AIA [52] models in rats. Pomegranate fruit extract, which is rich in EA [53], was shown to delay the onset and reduce the severity of arthritis in the CIA model in mice [54]. Therefore, the therapeutic effects of EA on AIA probably lie in its inhibition of leukocyte recruitment, down regulation of pro-inflammatory cytokines, and NO neutralising property.

RA pathogenesis is regulated by proinflammatory cytokines such as IL-1 $\beta$ and TNF- $\alpha$ that activate a broad array of intracellular signal transduction mechanisms that contribute to the progression of inflammatory arthritis, viz. leukocyte infiltration, cytokine networks formation, cartilage catabolism elevation, and anabolism suppression [7, 55-58]. Our results showed that arthritic control mice had higher levels of serum IL- $1 \beta$ and TNF- $\alpha$. We also found that EA treatment significantly reduced the serum levels of these pro-inflammatory cytokines, in agreement with

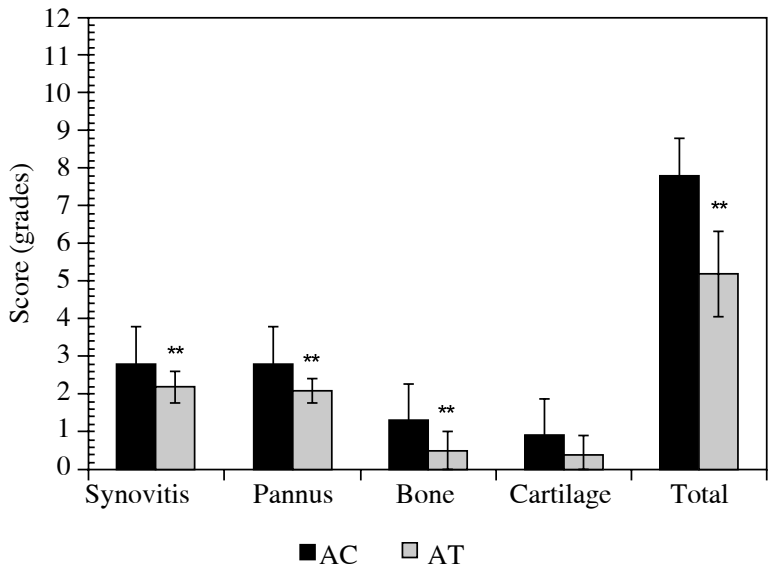

Fig. 3. The effect of ellagic acid treatment on the histopathological arthritis score of arthritic control (AC) and arthritic treated (AT) mice. The histopathological score of synovitis, pannus formation, bone resorption and cartilage destruction were examined per grades out of total score 12 . Data reported as mean \pm SD of 10 mice per each group. $* * p<0.01$

previous studies on different experimental models [21-26, 59-61]. The precise mechanism by which EA decreased levels of IL- $1 \beta$ and TNF- $\alpha$ is unclear and needs further investigation. However, Ahad et al. [61] suggest that EA suppressed the synthesis of IL-1 $\beta$ and TNF- $\alpha$ by inhibiting the NF- $\mathrm{NB}$ pathway. Furthermore, a growing body of evidence exists for the inhibitory activity of pomegranate extract containing EA on the activation of mitogen-activated protein kinases and NK-kB, which regulates the transcriptional activation of many inflammatory biomarkers [62-64]. Inflammatory genes that have been reported to be downregulated by pomegranate extract include TNF- $\alpha$, IL-1 $\beta$, MCP1, iNOS, COX-2, PGE2, and matrix metalloproteinases (MMPs) [36, 62, 63]. All these findings suggest that EA ameliorates AIA pathogenesis by inhibiting pro-inflammatory cytokines.

Table 2. Effect of ellagic acid treatment on serum cytokine profile

\begin{tabular}{lccccc}
\hline $\begin{array}{l}\text { Cytokine } \\
(\mathbf{p g} / \mathbf{m l})\end{array}$ & $\begin{array}{c}\text { Normal control } \\
(\mathbf{N C})\end{array}$ & $\begin{array}{c}\text { Normal treated } \\
(\mathbf{N T})\end{array}$ & $\begin{array}{c}\text { Arthritic control } \\
(\mathbf{A C})\end{array}$ & $\begin{array}{c}\text { Arthritic treated } \\
(\mathbf{A T})\end{array}$ & $p$ value \\
\hline IL-1 $\beta$ & $58.47 \pm 9.62^{\mathrm{a}}$ & $55.86 \pm 11.93^{\mathrm{a}}$ & $94.37 \pm 15.72^{\mathrm{b}}$ & $71.13 \pm 13.41^{\mathrm{c}}$ & $<0.01$ \\
\hline TNF- $\alpha$ & $45.02 \pm 7.11^{\mathrm{a}}$ & $42.98 \pm 8.52^{\mathrm{a}}$ & $100.79 \pm 14.16^{\mathrm{b}}$ & $75.23 \pm 12.84^{\mathrm{c}}$ & $<0.01$ \\
\hline IL-17 & $108.67 \pm 14.59^{\mathrm{a}}$ & $104.19 \pm 16.02^{\mathrm{a}}$ & $140.19 \pm 17.66^{\mathrm{b}}$ & $118.55 \pm 15.64^{\mathrm{a}}$ & $<0.01$ \\
\hline IFN- $\gamma$ & $101.545 \pm 15.67^{\mathrm{a}}$ & $128.263 \pm 15.24^{\mathrm{b}}$ & $97.354 \pm 18.95^{\mathrm{a}}$ & $121.091 \pm 16.18^{\mathrm{b}}$ & $<0.05$ \\
\hline TGF- $\beta$ & $147.56 \pm 17.27^{\mathrm{a}}$ & $146.55 \pm 19.22^{\mathrm{a}}$ & $128.41 \pm 18.19^{\mathrm{ab}}$ & $114.50 \pm 17.62^{\mathrm{b}}$ & $<0.01$ \\
\hline IL-10 & $124.35 \pm 15.52^{\mathrm{ad}}$ & $140.09 \pm 18.90^{\mathrm{a}}$ & $96.75 \pm 11.31^{\mathrm{c}}$ & $118.91 \pm 17.48^{\mathrm{d}}$ & $<0.01$ \\
\hline
\end{tabular}

Blood was collected by orbital puncture on the $21^{\text {st }}$ day after arthritis induction, and serum cytokine levels were estimated using sandwich ELISA. Data are expressed as mean \pm SD of 10 mice per group. For each cytokine, values not sharing common superscripts denote significant differences. 
Interleukin 17 plays a crucial role in the development of CIA by activating autoantigen specific cellular and humoral immune responses [14, 65]. Interleukin 17 has been shown to drive neutrophil differentiation, maturation, activation, and cytokine release; monocyte activation and cytokine release; and synovial fibroblast activation, cytokine and chemokine release, prostaglandin production, and MMP synthesis [66]. Inhibition or overexpression of IL-17 in the joints suppresses or worsens joint inflammation and damage, respectively [67]. Exogenous IL-17 strongly enhances cartilage damage and leads to erosion and chondrocyte death in the CIA mice model [68]. Antibodies against IL-17 are effective in the treatment of RA and psoriasis in clinical trials $[69,70]$. The present study clearly demonstrated that circulating levels of IL-17 significantly increased in arthritic control mice, whereas EA treatment reduced serum levels of IL-17 in arthritic mice, in harmony with a previous study that demonstrated that pomegranate juice rich in EA inhibited the synthesis of IL17 from PBMC [71]. Consistent with our data, Zhu et al. [72] reported that the level of IL-17 in the serum increased in the CIA mice model. These results suggested that EA alleviates RA pathogenesis by inhibited the synthesis of IL-17.

It has been shown that mice with a deficiency in IFN- $\gamma$ $[73,74]$ or IFN- $\gamma$ receptor [75-78] are more susceptible to CIA. These data indicate that deletion of the IFN- $\gamma$ response somehow disrupts an endogenous protective mechanism against CIA [79]. Therefore, IFN- $\gamma$ has been suggested to play a beneficial role in the CIA model in mice. The data of the current study showed that the serum levels of IFN- $\gamma$ significantly increased with EA treatment in both normal and arthritic mice. In an accord with our results, EA has been shown to stimulate IFN- $\gamma$ production in lymphocytes isolated from hepatitis B virus-e antigen transgenic mice [80]. Furthermore, macrophages treated with EA showed a $26.9 \%$ increased secretion of IFN- $\gamma$ [81]. Irmler et al. [82] reported that IFN- $\gamma$ has anti-inflammatory properties during the initial phase of the AIA model in mice, and concluded that IFN- $\gamma$ deficiency exerts disease-promoting effects, preferentially via IL-17-modulated pathways. These findings suggest that EA reduced RA-associated pathology by enhancing IFN- $\gamma$ secretion.

The role of TGF- $\beta$ in the development and pathogenesis of RA is conflicting. Kuruvilla et al. [83] and Thorbecke et al. [84] reported that TGF- $\beta$ protected against CIA in the mouse model because anti-TGF- $\beta$ increased CIA incidence and/or severity. However, $\mathrm{Xu}$ et al. [85] demonstrated that systemic or local blockade of TGF- $\beta$ activity in the subchondral bone attenuated articular cartilage degeneration in RA mouse/rat models. In addition, conditional deletion of TGF- $\beta$ receptor II (Tgfbr2) in nestin-positive cells also effectively halted progression of RA joint destruction. Our data demonstrated that EA treatment decreased circulating levels of TGF- $\beta$ in arthritic mice, but not in normal mice; such a decrease in TGF- $\beta$ level was not significantly different from that of arthritic control, but significantly decreased compared to that of normal control mice. Consistent with our results, Vanella et al. [86] demonstrated that EA reduced TGF- $\beta$ levels from LNCaP human prostatic cancer cell line. Furthermore, Ahad et al. [61] reported that treatment of diabetic rats with EA significantly lowered renal pathology and suppressed TGF- $\beta$ expression in renal tissues, and suggested that EA exerts its renal protective effect by suppressing the NK- $\kappa \mathrm{B}$ activation, which in turn leads to decreased expression of TGF- $\beta$.

On the other hand, IL-10 protein treatment has been shown to suppress established CIA model in mice [87, 88] and rats [89]. Interleukin 10-deficient mice had exacerbated CIA development, which was associated with increased production of IL-17 [90]. Our data clearly demonstrated that arthritic mice showed significantly decreased IL-10 levels as compared to the other tested groups. However, EA treatment significantly increased system levels of IL10 in arthritic mice to normal levels. Such a finding is in agreement with the data obtained by Chatterjee et al. [25], who demonstrated that treatment of gastric ulcerated mice with EA increase IL-10 level, and Cornélio Favarin et al. [27], who reported that EA treatment led to an increase level in IL-10 in bronchoalveolar lavage fluid of acute lung injury murine model. In addition, EA acid exhibited a potent anti-inflammatory effect against carrageenan-induced inflammation in rats with an increased IL-10, and a decrease in TNF- $\alpha$ and IL-1 $\beta$ [91]. Recently, different approaches have been used to prevent and/or treat the CIA model in mice by enhancing IL-10 production and suppressing inflammatory cytokines through either oral administration of type II collagen [92], IL-10 gene therapy [93], treatment with ES-62, a molecule secreted by the parasitic filarial nematodes [94], or Salmonella-colonisation factor antigen I (CFA/I) to stimulate Treg cells [95]. Therefore, we suggest that EA alleviates AIA-associated pathology in mice by inhibiting inflammatory cytokines (TNF- $\alpha$, IL-1 $\beta$, IL-17) and by stimulating anti-inflammatory cytokine (IL-10) production.

\section{Conclusions}

Taking together, the data from this study demonstrate that EA treatment ameliorated AIA associated pathology in mice model, as shown by the reduction of foot paw oedematous swelling, synovitis, pannus formation, and bone resorption. EA mediated its anti-arthritic effect through downregulation of pro-inflammatory cytokines and upregulation of anti-inflammatory cytokines. Therefore, EA could provide an additional therapeutic strategy for RA, 
particularly in situations in which the patient has elevated levels of pro-inflammatory cytokines.

The present study was financially supported by a research grant from Taif University, Kingdom of Saudi Arabia (Number: 1-435-2215).

The authors declare no conflict of interest.

\section{References}

1. Ibold Y, Frauenschuh S, Kaps C, et al. (2007): Development of a high-throughput screening assay based on the 3-dimensional pannus model for rheumatoid arthritis. J Biomol Screen 12: 956-965.

2. Epstein FH, Choy EH, Panayi GS (2001): Cytokine pathways and joint inflammation in rheumatoid arthritis. N Engl J Med 344: 907-916.

3. Majithia V, Geraci SA (2007): Rheumatoid arthritis: diagnosis and management. Am J Med 120: 936-939.

4. Choy E (2012): Understanding the dynamics: pathways involved in the pathogenesis of rheumatoid arthritis. Rheumatology 51: v3-v11.

5. Arend WP, Dayer JM (1995): Inhibition of the production and effects of interleukins-1 and tumor necrosis factor $\alpha$ in rheumatoid arthritis. Arthritis Rheum 38: 151-160.

6. Barksby H, Lea S, Preshaw P, et al. (2007): The expanding family of interleukin-1 cytokines and their role in destructive inflammatory disorders. Clin Exp Immunol 149: 217-225.

7. Firestein GS (2003): Evolving concepts of rheumatoid arthritis. Nature 423: 356-361.

8. Moreland LW, Schiff MH, Baumgartner SW, et al. (1999): Etanercept therapy in rheumatoid arthritis: a randomized, controlled trial. Ann Intern Med 130: 478-486.

9. Feldmann M, Maini RN (2001): Anti-TNF alpha therapy of rheumatoid arthritis: what have we learned? Annu Rev Immunol 19: 163-196.

10. Shmerling RH (1998): Rheumatoid arthritis. Drugs Today (Barc) 34: 649-653

11. Simon AK, Seipelt E, Sieper J (1994): Divergent T-cell cytokine patterns in inflammatory arthritis. Proc Natl Acad Sci 91: 8562-8566.

12. van der Graaff WL, Prins AP, Dijkmans BA, et al. (1998): Prognostic value of Th1/Th2 ratio in rheumatoid arthritis. Lancet 351: 1931.

13. Leipe J, Grunke M, Dechant C, et al. (2010): Role of Th17 cells in human autoimmune arthritis. Arthritis Rheum 62: 2876-2885.

14. Nakae S, Nambu A, Sudo K, et al. (2003): Suppression of immune induction of collagen-induced arthritis in IL-17-deficient mice. J Immunol 171: 6173-6177.

15. Bush KA, Farmer KM, Walker JS, et al. (2002): Reduction of joint inflammation and bone erosion in rat adjuvant arthritis by treatment with interleukin- 17 receptor IgG1 Fc fusion protein. Arthritis Rheum 46: 802-805.

16. Fujimoto M, Serada S, Mihara M, et al. (2008): Interleukin-6 blockade suppresses autoimmune arthritis in mice by the inhibition of inflammatory Th17 responses. Arthritis Rheum 58: 3710-3719.

17. de Ancos B, González EM, Cano MP (2000): Ellagic acid, vitamin $\mathrm{C}$, and total phenolic contents and radical scavenging capacity affected by freezing and frozen storage in raspberry fruit. J Agric Food Chem 48: 4565-4570.

18. Sellappan S, Akoh CC, Krewer G (2002): Phenolic compounds and antioxidant capacity of Georgia-grown blueberries and blackberries. J Agric Food Chem 50: 2432-2438.

19. Mertens-Talcott SU, Talcott ST, Percival SS (2003): Low Concentrations of Quercetin and Ellagic Acid Synergistically Influence Proliferation, Cytotoxicity and Apoptosis in MOLT-4 Human Leukemia Cells. J Nutr 133: 2669-2674.

20. Yu Y-M, Wang Z-H, Liu C-H, et al. (2007): Ellagic acid inhibits IL-1 $\beta$-induced cell adhesion molecule expression in human umbilical vein endothelial cells. Br J Nutr 97: 692-698.

21. Anderson KC, Teuber SS (2010): Ellagic acid and polyphenolics present in walnut kernels inhibit in vitro human peripheral blood mononuclear cell proliferation and alter cytokine production. Ann N Y Acad Sci 1190: 86-96.

22. Chao PC, Hsu CC, Yin MC (2009): Anti-inflammatory and anti-coagulatory activities of caffeic acid and ellagic acid in cardiac tissue of diabetic mice. Nutr Metab (Lond) 6: 33.

23. Chao CY, Mong MC, Chan KC, et al. (2010): Anti-glycative and anti-inflammatory effects of caffeic acid and ellagic acid in kidney of diabetic mice. Mol Nutr Food Res 54: 388-395.

24. Bae JY, Choi JS, Kang SW, et al. (2010): Dietary compound ellagic acid alleviates skin wrinkle and inflammation induced by UV-B irradiation. Exp Dermatol 19: e182-e190.

25. Chatterjee A, Chatterjee S, Das S, et al. (2012): Ellagic acid facilitates indomethacin-induced gastric ulcer healing via COX-2 up-regulation. Acta Biochim Biophys Sin (Shanghai) 44: 565-576.

26. Mo J, Panichayupakaranant P, Kaewnopparat N, et al. (2013): Topical anti-inflammatory and analgesic activities of standardized pomegranate rind extract in comparison with its marker compound ellagic acid in vivo. J Ethnopharmacol 148: 901-908.

27. Cornélio Favarin D, Martins Teixeira M, Lemos de Andrade E, et al. (2013): Anti-inflammatory effects of ellagic acid on acute lung injury induced by acid in mice. Mediators Inflamm 2013: 164202.

28. Ahmad SF, Khan B, Bani S, et al. (2006): Amelioration of adjuvant-induced arthritis by ursolic acid through altered Th1/ Th2 cytokine production. Pharmacol Res 53: 233-240.

29. Ahmad SF, Zoheir KM, Bakheet SA, et al. (2014): Poly (ADP-ribose) polymerase-1 inhibitor modulates T regulatory and IL-17 cells in the prevention of adjuvant induced arthritis in mice model. Cytokine 68: 76-85.

30. Soh PN, Witkowski B, Olagnier D, et al. (2009): In vitro and in vivo properties of ellagic acid in malaria treatment. Antimicrob Agents Chemother 53: 1100-1106.

31. Shruthi S, Sujan Ganapathy P, Rakesh Kumar S, et al. (2014): In vivo, In vitro anti-arthritic studies of Ellagic acid from Kirganelia reticulata Baill and its molecular docking. J App Pharm Sci 4: 024-031.

32. Wu Y, Liu J, Feng X, et al. (2005): Synovial fibroblasts promote osteoclast formation by RANKL in a novel model of spontaneous erosive arthritis. Arthritis Rheum 52: 3257-3268.

33. Nasu Y, Nishida K, Miyazawa S, et al. (2008): Trichostatin A, a histone deacetylase inhibitor, suppresses synovial inflammation and subsequent cartilage destruction in a collagen antibody-induced arthritis mouse model. Osteoarthritis Cartilage 16: 723-732.

34. González-Chávez SA, Pacheco-Tena C, Macías-Vázquez CE, et al. (2013): Assessment of different decalcifying protocols on Osteopontin and Osteocalcin immunostaining in whole 
bone specimens of arthritis rat model by confocal immunofluorescence. Int J Clin Exp Pathol 6: 1972.

35. Sancho D, Gomez M, Viedma F, et al. (2003): CD69 downregulates autoimmune reactivity through active transforming growth factor-beta production in collagen-induced arthritis. J Clin Invest 112: 872-882.

36. Ahmed S, Anuntiyo J, Malemud CJ, et al. (2005): Biological basis for the use of botanicals in osteoarthritis and rheumatoid arthritis: a review. Evid Based Complement Alternat Med 2: 301-308.

37. Shen C-L, Smith BJ, Lo D-F, et al. (2012): Dietary polyphenols and mechanisms of osteoarthritis. J Nutr Biochem 23: 1367-1377.

38. Brackertz D, Mitchell GF, Mackay IR (1977): Antigen - induced arthritis in mice. Arthritis Rheum 20: 841-850.

39. Doyle B, Griffiths LA (1980): The metabolism of ellagic acid in the rat. Xenobiotica 10: 247-256.

40. Teel RW, Martin RM (1988): Disposition of the plant phenol ellagic acid in the mouse following oral administration by gavage. Xenobiotica 18: 397-405.

41. Landete JM (2011): Ellagitannins, ellagic acid and their derived metabolites: a review about source, metabolism, functions and health. Food Res Int 44: 1150-1160.

42. Larrosa M, Gonzalez-Sarrias A, Garcia-Conesa MT, et al. (2006): Urolithins, ellagic acid-derived metabolites produced by human colonic microflora, exhibit estrogenic and antiestrogenic activities. J Agric Food Chem 54: 1611-1620.

43. Mertens-Talcott SU, Jilma-Stohlawetz P, Rios J, et al. (2006): Absorption, metabolism, and antioxidant effects of pomegranate (Punica granatum 1.) polyphenols after ingestion of a standardized extract in healthy human volunteers. J Agric Food Chem 54: 8956-8961.

44. Seeram NP, Henning SM, Zhang Y, et al. (2006): Pomegranate juice ellagitannin metabolites are present in human plasma and some persist in urine for up to 48 hours. J Nutr 136: 2481-2485.

45. Koch AE (2005): Chemokines and their receptors in rheumatoid arthritis: future targets? Arthritis Rheum 52: 710-721.

46. Ahmed S, Wang N, Hafeez BB, et al. (2005): Punica granatum L. extract inhibits IL-1 $\beta$-Induced expression of matrix metalloproteinases by inhibiting the activation of MAP kinases and NF- $\kappa B$ in human chondrocytes in vitro. J Nutr 135: 2096-2102.

47. Van Vollenhoven R, Soriano A, McCarthy P, et al. (1988): The role of immunity to cartilage proteoglycan in adjuvant arthritis. Intravenous injection of bovine proteoglycan enhances adjuvant arthritis. J Immunol 141: 1168-1173.

48. Feige U, Schulmeister A, Mollenhauer J, et al. (1994): A constitutive $65 \mathrm{kDa}$ chondrocyte protein as a target antigen in adjuvant arthritis in Lewis rats. Autoimmunity 17: 233-239.

49. Van de Langerijt A, Lent P, Hermus A, et al. (1994): Susceptibility to adjuvant arthritis: relative importance of adrenal activity and bacterial flora. Clin Exp Immunol 97: 33-38.

50. Bulani V, Kothavade P, Nagmoti D, et al. (2014): 19: Ellagic acid hydroxypropyl- $\beta$-cyclodextrin inclusion complex alleviates adjuvant-induced arthritis: Attenuation of oxidative stress and inflammatory mediators. Cytokine 70: 32 .

51. Figueira M, Câmara M, Direito R, et al. (2014): Chemical characterization of a red raspberry fruit extract and evaluation of its pharmacological effects in experimental models of acute inflammation and collagen-induced arthritis. Food Funct 5: 3241-3251.
52. Jean-Gilles D, Li L, Ma H, et al. (2012): Anti-inflammatory effects of polyphenolic-enriched red raspberry extract in an antigen-induced arthritis rat model. J Agric Food Chem 60: 5755-5762.

53. Gil MI, Tomás-Barberán FA, Hess-Pierce B, et al. (2000): Antioxidant activity of pomegranate juice and its relationship with phenolic composition and processing. J Agric Food Chem 48: 4581-4589.

54. Shukla M, Gupta K, Rasheed Z, et al. (2008): Consumption of hydrolyzable tannins-rich pomegranate extract suppresses inflammation and joint damage in rheumatoid arthritis. Nutrition 24: 733-743.

55. Firestein GS, Manning AM (1999): Signal transduction and transcription factors in rheumatic disease. Arthritis Rheum 42: 609-621.

56. Pope RM (2002): Apoptosis as a therapeutic tool in rheumatoid arthritis. Nat Rev Immunol 2: 527-535.

57. Lavanya R, Maheshwari SU, Harish G, et al. (2010): Investigation of in-vitro anti-inflammatory, anti-platelet and anti-arthritic activities in the leaves of Anisomeles malabarica Linn. Res J Pharm Biol Chem Sci 1: 745-752.

58. Kapoor M, Martel-Pelletier J, Lajeunesse D, et al. (2011): Role of proinflammatory cytokines in the pathophysiology of osteoarthritis. Nat Rev Rheumatol 7: 33-42.

59. Umesalma S, Sudhandiran G (2010): Differential inhibitory effects of the polyphenol ellagic acid on inflammatory mediators NF-kappaB, iNOS, COX-2, TNF-alpha, and IL-6 in 1,2-dimethylhydrazine-induced rat colon carcinogenesis. Basic Clin Pharmacol Toxicol 107: 650-655.

60. Jensen JD, Dunn JH, Luo Y, et al. (2011): Ellagic acid inhibits melanoma growth in vitro. Dermatol reports 3: e36.

61. Ahad A, Ganai AA, Mujeeb M, et al. (2014): Ellagic acid, an $\mathrm{NF}-\kappa \mathrm{B}$ inhibitor, ameliorates renal function in experimental diabetic nephropathy. Chem Biol Interact 219: 64-75.

62. Afaq F, Saleem M, Krueger CG, et al. (2005): Anthocyanin- and hydrolyzable tannin-rich pomegranate fruit extract modulates MAPK and NF-kappaB pathways and inhibits skin tumorigenesis in CD-1 mice. Int J Cancer 113: 423-433.

63. Rasheed Z, Akhtar N, Anbazhagan AN, et al. (2009): Polyphenol-rich pomegranate fruit extract (POMx) suppresses PMACI-induced expression of pro-inflammatory cytokines by inhibiting the activation of MAP Kinases and NF- $\mathrm{KB}$ in human KU812 cells. J Inflamm (Lond) 6: 1.

64. Bishayee A, Thoppil RJ, Darvesh AS, et al. (2013): Pomegranate phytoconstituents blunt the inflammatory cascade in a chemically induced rodent model of hepatocellular carcinogenesis. J Nutr Biochem 24: 178-187.

65. Lubberts E, Koenders MI, Oppers-Walgreen B, et al. (2004): Treatment with a neutralizing anti-murine interleukin-17 antibody after the onset of collagen-induced arthritis reduces joint inflammation, cartilage destruction, and bone erosion. Arthritis Rheum 50: 650-659.

66. Weaver CT, Hatton RD, Mangan PR, et al. (2007): IL-17 family cytokines and the expanding diversity of effector T cell lineages. Annu Rev Immunol 25: 821-852.

67. Lubberts E, Koenders MI, van den Berg WB (2005): The role of T-cell interleukin-17 in conducting destructive arthritis: lessons from animal models. Arthritis Res Ther 7: 29-37.

68. Lubberts E, Joosten LA, van de Loo FA, et al. (2002): Overexpression of IL-17 in the knee joint of collagen type II immunized mice promotes collagen arthritis and aggravates joint destruction. Inflamm Res 51: 102-104. 
69. Genovese M, Van den Bosch F, Roberson S, et al. (2010): LY2439821, a humanized anti-interleukin-17 monoclonal antibody, in the treatment of patients with rheumatoid arthritis: A phase I randomized, double-blind, placebo-controlled, proof-of-concept study. Arthritis Rheum 62: 929-939.

70. Hueber W, Patel DD, Dryja T, et al. (2010): Effects of AIN457, a fully human antibody to interleukin-17A, on psoriasis, rheumatoid arthritis, and uveitis. Sci Transl Med 2: 52ra72-52ra72.

71. Filannino P, Azzi L, Cavoski I, et al. (2013): Exploitation of the health-promoting and sensory properties of organic pomegranate (Punica granatum L.) juice through lactic acid fermentation. Int J Food Microbiol 163: 184-192.

72. Zhu M, Xu Q, Li X-L, et al. (2014): Modulating effects of leflunomide on the balance of Th17/Treg cells in collageninduced arthritis DBA/1 mice. Cent Eur J Immunol 39: 152158.

73. Guedez YB, Whittington KB, Clayton JL, et al. (2001): Genetic ablation of interferon $\gamma$ up - regulates interleukin $-1 \beta$ expression and enables the elicitation of collagen - induced arthritis in a nonsusceptible mouse strain. Arthritis Rheum 44: 2413-2424.

74. Chu C, Song Z, Mayton L, et al. (2003): IFN $\gamma$ deficient C57BL/6 (H-2b) mice develop collagen induced arthritis with predominant usage of $\mathrm{T}$ cell receptor $\mathrm{V} \beta 6$ and $\mathrm{V} \beta 8$ in arthritic joints. Ann Rheum Dis 62: 983-990.

75. Vermeire K, Heremans H, Vandeputte M, et al. (1997): Accelerated collagen-induced arthritis in IFN-gamma receptor-deficient mice. J Immunol 158: 5507-5513.

76. Manoury-Schwartz B, Chiocchia G, Bessis N, et al. (1997): High susceptibility to collagen-induced arthritis in mice lacking IFN-gamma receptors. J Immunol 158: 5501-5506.

77. Matthys P, Vermeire K, Mitera T, et al. (1999): Enhanced autoimmune arthritis in IFN- $\gamma$ receptor-deficient mice is conditioned by mycobacteria in Freund's adjuvant and by increased expansion of Mac-1+ myeloid cells. J Immunol 163: 3503-3510.

78. De Klerck B, Carpentier I, Lories RJ, et al. (2004): Enhanced osteoclast development in collagen-induced arthritis in interferon-gamma receptor knock-out mice as related to increased splenic CD11b+ myelopoiesis. Arthritis Res Ther 6: R220-R231.

79. Kelchtermans H, De Klerck B, Mitera T, et al. (2005): Defective CD4+ CD25+ regulatory $\mathrm{T}$ cell functioning in collagen-induced arthritis: an important factor in pathogenesis, counter-regulated by endogenous IFN-gamma. Arthritis Res Ther 7: R402-R415.

80. Kang EH, Kown TY, Oh GT, et al. (2006): The flavonoid ellagic acid from a medicinal herb inhibits host immune tolerance induced by the hepatitis B virus-e antigen. Antiviral Res 72: 100-106.

81. Dubey A, Park DW, Kwon JE, et al. (2015): Investigation of the biological and anti-cancer properties of ellagic acid-encapsulated nano-sized metalla-cages. Int J Nanomedicine 10: 227-240.

82. Irmler IM, Gajda M, Bräuer R (2007): Exacerbation of antigen-induced arthritis in IFN- $\gamma$-deficient mice as a result of unrestricted IL-17 response. J Immunol 179: 6228-6236.

83. Kuruvilla A, Shah R, Hochwald G, et al. (1991): Protective effect of transforming growth factor beta 1 on experimental autoimmune diseases in mice. Proc Natl Acad Sci 88: 29182921.
84. Thorbecke G, Shah R, Leu C, et al. (1992): Involvement of endogenous tumor necrosis factor alpha and transforming growth factor beta during induction of collagen type II arthritis in mice. Proc Natl Acad Sci 89: 7375-7379.

85. Xu X, Zheng L, Bian Q, et al. (2015): Aberrant activation of TGF- $\beta$ in subchondral bone at the onset of rheumatoid arthritis joint destruction. J Bone Miner Res 30: 2033-2043.

86. Vanella L, Di Giacomo C, Acquaviva R, et al. (2013): Apoptotic markers in a prostate cancer cell line: Effect of ellagic acid. Oncol Rep 30: 2804-2810.

87. Tanaka Y, Otsuka T, Hotokebuchi T, et al. (1996): Effect of IL-10 on collagen-induced arthritis in mice. Inflamm Res 45: 283-288.

88. Walmsley M, Katsikis PD, Abney E, et al. (1996): Interleukin-10 inhibition of the progression of established collageninduced arthritis. Arthritis Rheum 39: 495-503.

89. Persson S, Mikulowska A, Narula S, et al. (1996): Interleukin-10 suppresses the development of collagen type II-induced arthritis and ameliorates sustained arthritis in rats. Scand J Immunol 44: 607-614.

90. Ye L, Wen Z, Li Y, et al. (2014): Interleukin-10 attenuation of collagen-induced arthritis is associated with suppression of interleukin-17 and retinoid-related orphan receptor $\gamma t$ production in macrophages and repression of classically activated macrophages. Arthritis Res Ther 16: R96.

91. El-Shitany NA, El-Bastawissy EA, El-desoky K (2014): Ellagic acid protects against carrageenan-induced acute inflammation through inhibition of nuclear factor kappa B, inducible cyclooxygenase and proinflammatory cytokines and enhancement of interleukin-10 via an antioxidant mechanism. Int Immunopharmacol 19: 290-299.

92. Min S-Y, Hwang S-Y, Park K-S, et al. (2004): Induction of IL-10-producing CD4+ CD25+ T cells in animal model of collagen-induced arthritis by oral administration of type II collagen. Arthritis Res Ther 6: R213-219.

93. Vermeij EA, Broeren MG, Bennink MB, et al. (2015): Disease-regulated local IL-10 gene therapy diminishes synovitis and cartilage proteoglycan depletion in experimental arthritis. Ann Rheum Dis 74: 2084-2091.

94. Rodgers DT, Pineda MA, McGrath MA, et al. (2014): Protection against collagen-induced arthritis in mice afforded by the parasitic worm product, ES-62, is associated with restoration of the levels of interleukin - 10 - producing B cells and reduced plasma cell infiltration of the joints. Immunology 141: 457-466.

95. Maddaloni M, Kochetkova I, Jun S, et al. (2015): Milk-based nutraceutical for treating autoimmune arthritis via the stimulation of IL-10-and TGF- $\beta$-producing CD39+ Regulatory T cells. PloS One 10: e0117825. 